\title{
Neurovascular Bundle
}

National Cancer Institute

\section{Source}

National Cancer Institute. Neurovascular Bundle. NCI Thesaurus. Code C74603.

A body structure consisting of nerves traveling together with arteries, veins, and/or lymphatics. 